-ORIGINAL ARTICLE

Volume 12 Issue 12020

DOI: 10.21315/eimj2020.12.1.5

ARTICLE INFO

Submitted: 07-01-2020

Accepted: 21-02-2020

Online: 10-04-2020

\section{How Motivation Correlates with Academic Burnout: Study Conducted in Undergraduate Medical Students}

\author{
Estivana Felaza, Ardi Findyartini, Daniar Setyorini, Rita Mustika
}

Medical Education Department, Faculty of Medicine, Universitas Indonesia, INDONESIA

To cite this article: Felaza E, Findyartini A, Setyorini D, Mustika R. How motivation correlates with academic burnout: study conducted in undergraduate medical students. Education in Medicine Journal. 2020;12(1): 43-52. https://doi.org/10.21315/eimj2020.12.1.5

To link to this article: https://doi.org/10.21315/eimj2020.12.1.5

\begin{abstract}
Burnout is found among medical students as they become overwhelmed by stressors. On the other hand, students' motivation act as the force that maintains learning. This study aims to capture the association between motivation type and burnout in students. This cross-sectional study involved students across all year levels with a total of 1,036 students participated in the study. Data was collected using Academic Motivation Scale to determine type of motivation, and Maslach Burnout Inventory to measure burnout's components (emotional exhaustion, cynicism and perception of personal accomplishment). Correlations and multivariate analyses were conducted to discover associations between motivation, burnout components and performance. Significant negative correlations were found between motivation type and perception of personal accomplishment in preclinical year $(\mathrm{PCY}) 2(r=-0.206 ; p=0.004)$, clinical year $(\mathrm{CY}) 1(r=-0.242 ; p=0.000)$, and CY2 $(r=-0.189 ; p=0.012)$. In PCY1 the correlation was significantly positive $(r=0.061 ; p=0.003)$, while in PCY3 no significant correlation was found. Negative correlations found indicate that the more external the motivation, the lower the perception of personal accomplishment. Motivation types correlates with perception of personal accomplishment as one of the subscales of burnout; showing perceptions' tendency to lowered as motivation becomes more external. This study highlights the importance of addressing students' motivation in preventing burnout. Efforts to strengthen intrinsic motivations may help develop better perceptions of personal accomplishment and protect students from burnout.
\end{abstract}

Keywords: Motivation, Students, Self-efficacy, Burnout

CORRESPONDING AUTHOR

Estivana Felaza, Medical Education Department, Faculty of Medicine, Universitas Indonesia, Salemba Raya 6, Jakarta 10430, Indonesia | Email : estivanafelaza@gmail.com

\section{INTRODUCTION}

The phenomenon of mental and physical exhaustion during medical education has been documented in several studies as burnout. In the United States, almost half of the medical students enrolled in major institutions experience burnout during their education (1). Burnout is considered as a result of a shift in idealism, as fascination with the medical world is overshadowed by the routinity and burden of work. Even though at first the term was used mostly in the context of service-related professions, it has now been discovered that burnout occurs early, even during 
the medical education process. Academic burdens, social pressures and unsupportive learning environments contribute to development of burnout. Students with burnout experience emotional exhaustion, depersonalisation and low perceptions of personal accomplishments, which later are identified as the three components of burnout (1). Without proper interventions, this condition might lead to depression and has been associated with suicidal ideation (1).

Students' motivation can be seen as the driving force that ensures learning takes place. Based on self-determination theory, motivation has been modelled as a spectrum ranging from the self-determined end, also known as intrinsic motivation, to extrinsic motivation and to amotivation at the other end (2). The source of intrinsic motivation emanates from within, whereas extrinsic motivation relies more on external factors, such as rewards for learning. Studies have shown that intrinsically motivated students tend to use deep learning approach that is correlated with better academic performance. These students also showed higher intention to continue their medical studies and become lifelong learners $(2,3)$. In medical education, altruism can also be considered an intrinsic type of motivation, as students strive to learn with the intention of being able to help others later as future doctors (4). On the other hand, extrinsic motivation is considered as a controlled type of motivation because of the way individuals' motives for learning are controlled by an external cause $(2,5)$. Furthermore, four motivational profiles have been introduced by namely high intrinsic high controlled (HIHC) type which reflects high intrinsic motivation/interest and controlled/status motivation and high intrinsic low controlled (HILC) type which reflects high intrinsic motivation/interest and low controlled/status motivation. In addition, low intrinsic high controlled (LIHC) type refers to low intrinsic motivation/interest and high controlled/status motivation, whereas both intrinsic motivation/interest and controlled/status motivation are low in low intrinsic low controlled (LILC) motivational type (3). Individuals with HIHC motivational profiles possess both high intrinsic and extrinsic motivation for conducting their learning efforts, while for those with HILC, the majority of the drive to learn comes from their intrinsic source of motivation. Due to the more stable nature of intrinsic motivation, these two types were predicted to have better performance compared to the others $(2,3)$. On the other hand, individuals with LIHC based their motivation from external sources. The last type, LILC was the most vulnerable, because their low levels of motivation from either internal or external source.

While burnout can be conceptualised as students' decreased passion for learning, motivation can be seen as the spirit that keeps the flame alive. Intrinsic motivation is supported by three components: students' sense of autonomy toward their actions, a feeling of competence in their learning and a sense of relatedness to their environment. A positive perception of one's capability (competence) to master certain tasks makes students more motivated to learn. As students feel supported and belong as part of their educational environment (relatedness), their intrinsic motivation increases (2). Based on Bandura's social cognitive theory (SCT), an individual's behaviour results from interactions between personal factors (motivation, self-efficacy and attributions), behaviour (previous successful or failed behaviour, and self regulation process), and the environment (social support) (5).

Self-regulation indicates that individuals orient their behaviour toward certain standards and continually analyse the discrepancies found between their performance and the standards they have set. As individuals analyse their accomplishments and progress in reaching their goals, their self-efficacy would be affected. Self-efficacy defined as a belief in one's capabilities to conduct the necessary course of action to achieve a desired goal, was appraised by analysing actual performance, experiences, forms of persuasion and physiological reactions. Students rated their performance against the intended standard they had set 
for themselves and by comparing it with the performance of other students. Perceived success would enhance self-efficacy, whereas failures would lower it (6). This ability seemed to be lacking in individuals experiencing burnout. When individuals with burnout compare their current performance with their set of desired standards, their performance tends to be seen as unsatisfying. This could be the result of utilising an unobjective method of perceiving one's performance, or it could be due to setting unrealistic standards for themselves. Several studies have found a negative correlation between self-regulation and burnout, indicating that increased self-regulation ability might result in decreased burnout (7).

Self-efficacy can also be strengthened by receiving positive feedback from others and by detecting decreased anxiety, as anxiety was considered a physiological reaction associated with failing to conduct certain tasks $(8,9)$. Self-efficacy was found to be positively correlated with intrinsic motivation in which high self-efficacy would contribute to increased intrinsic motivation $(10,11)$. Correlation analysis from a study on burnout and motivation has shown that burnout is negatively correlated with self-efficacy and with intrinsic motivation altogether (12).

Furthermore, individuals with burnout tend to detach themselves from their environment (not seeing themselves as part of their environment would then lead to cynicism) and from their own performance (resulting in a low perception of personal accomplishment). Due to the detachment, individuals with burnout might also attribute their performance failure to external factors (the difficulties of the task, or lack of chances) and perceive the result of their performance as being beyond their control. This might lead students' motivation to decrease because they cannot see any hope for future improvements. An internal locus of control (attributing the current performance to factors that are changeable within the individual) is considered a healthier attribute and correlates better with success (13).
Several studies have shown relationship between motivation and burnout. A study conducted in China on secondary students showed that students without burnout had the highest scores on intrinsic motivation, while distressed students were those with high scores on extrinsic motivation and amotivation (14). A study on career choice motivation in medical students, showed that a lack of altruistic motivation correlated with the burnout variables of cynicism and reduced academic efficacy (4). Kusurkar et al. have profiled undergraduate medical students' motivation in The Netherlands context (3). Given the challenge of undergraduate medical students to commit to studying medicine for a long period of time and that medical schools should be able to support the students along the way by considering contextual aspects such as culture, resources, etc, current authors aim to explore the association of students' motivation type, burnout and academic performance, especially in Indonesia context.

\section{METHOD}

\section{Participants}

The study was conducted with students of the undergraduate medical programme at the Faculty of Medicine, Universitas Indonesia (FMUI) in 2018. The programme consists of seven to eight semesters of the pre-clinical phase and four semesters of the clinical phase. A competency-based curriculum with an integrated, student-centred and problembased approach has been implemented in the past 12 years.

\section{Instruments}

In this cross-sectional study, questionnaires were distributed to first- to fifth-year students. This study used total sampling approach and students voluntarily filled out the questionnaires. Motivation was measured using the Academic Motivation Scale (AMS), a 28 -item questionnaire that aimed to identify students' type of motivation for learning, 
while the Maslach Burnout InventoryStudent Survey (MBI-SS) was used to measure the burnout experienced during the education process. All the instruments were presented in the Indonesian language and have been validated in the previous study with good internal consistencies; 0.913 for MBI-SS and 0.950 for AMS respectively (15). Students' academic performance was measured by their grade point average (GPA) in respective semesters.

Data derived from the questionnaires were analysed using SPSS 22.0. Based on the AMS results, students were grouped into HIHC, HILC, LIHC and LILC or amotivation categories (3). Scores on burnout were measured based on its three scales: emotional exhaustion, depersonalisation and perception of personal accomplishment (14). For numerical data, a test of normality was conducted to measure the distribution of the results. A correlation between motivation and the components of burnout was identified and multiple regression was conducted to confirm the results and identify confounding factors.

This study has been approved by Research Ethics Committee of FMUI No. 451/UN2. F1/ETIK/IV/2018. Information regarding the study was given to the participants and those agreed to participate voluntarily filled out the questionnaires.

\section{RESULTS}

A total of 1,036 Year 1 to Year 5 students responded to the questionnaires with a response rate per year level ranging from $89 \%$ to $98 \%$. Two incomplete questionnaires were excluded from the analysis. The respondents in the current study consisted of 439 female students (42.46\%) and 595 male students (57.54\%) across all year levels at FMUI (see Table 1).

Analysis on motivation type was conducted based on the burnout components (emotional exhaustion, cynicism and perception of personal accomplishment) and academic performance. The results showed a negative correlation between motivation type and perception of personal accomplishment in Year 1, Year 2 and Clinical Year (CY) 2 (with $r$ ranging from -0.229 to -0.166 and the $p$-value ranging from 0.001 to 0.028 ) (see Table 2).

To further confirm the correlations between motivation type and the components of burnout (cynicism and perception of personal accomplishment), multivariate analysis was conducted. Statistically significant associations were found between motivation and perception of personal accomplishment in all year levels, except Year 3. Students whose motivation show a more extrinsic form and amotivation (with intrinsic motivation diminished), tend to have a decreased perception of personal accomplishment ( $r$ ranging from -0.138 to -0.242 ), except in Year 1, when a weak positive correlation was found $(r=0.061)$ (see Table 3).

\section{DISCUSSION}

The aim of this study was to seek correlation between motivation, components of burnout and academic performance. Motivation was found to be corrrelated with burnout on one of its components of perception of personal accomplishment. Students with less intrinsic motivation and more extrinsic (controlled) motivation tend to have lower perception of accomplishment. This phenomenon was found in Pre-Clinical Year (PCY) 2, CY 1 and CY 2. A similar finding was evident in a study conducted in China, which showed that students with high intrinsic motivation did not experience burnout and on the contrary, those with high extrinsic motivation tend to experience burnout (14). Other study in Korean students showed the role of motivation in mediating the relation between the type of perfectionism and academic burnout. Selforiented perfectionism, which defined as setting high expectations and goals for one self, is closely linked to intrinsic motivation, 
which in turn negatively related to academic burnout. While on the other hand, sociallyprescribed perfectionism, which defined as striving to meet the expectations of others, is linked to extrinsic motivation, which positively related to burnout (16). However, these studies did not specifically explore the relationship between type of motivation and each component of burnout. The association between intrinsic motivation and the components of burnout was further confirmed in a study involving medical students in Hungary. Altruistic motivation, which can be considered an intrinsic motivation, was found to be associated with low cynicism and a higher perception of personal accomplishment (6).

The negative correlation between type of motivation and perception of personal accomplishment in this study most likely involved the concept of self-efficacy. Study using person-oriented approach on burnout showed that burnout level correlates negatively with self-efficacy and intrinsic motivation. Therefore, students with higher burnout level tend to have lower selfefficacy and lower intrinsic motivation (12). Bandura's theory (8) stated that self-efficacy can be promoted by mastery experiences (successful similar experience in the past), vicarious learning (observing successful similar experience from others), social persuasion and psychological states. Aside from mastery experience, psychological states are the most important source of efficacy beliefs. When students experience stress and negative thoughts, these negative affects can lower their perceptions of capability and reinforces their fear of not being able to perform adequately (lower their self-efficacy).

In the present study, a significantly negative and low correlation between motivation type and perception of personal accomplishment was not found similarly across year levels (Table 3). In Year 1, the correlation was positive, meaning as motivation moves into a more extrinsic form, perception of personal accomplishment increases, whereas in Year 3 no significant correlation was found. The complex relationship between motivation and perception of personal accomplishment, as well as the adaptation process that the first-year students were experiencing, could be attributed as the factors contributing to the positive correlation between motivation and perception of personal accomplishment in Year 1.

First-year students were likely to have limited information regarding the educational process they were experiencing as opposed to their more senior peers. Being selected as medical students through the selection process itself enhances students' intrinsic motivation, as it accomodates three components of intrinsic motivation (autonomy, perceived competence and a sense of belonging to a special group selected for medicine) (17). As found in the present study, most first-year students showed HIHC types of motivation (Table 1). Explanations for the correlation found between combination of intrinsic and extrinsic motivation (as reflected in HIHC type) and the perception of personal accomplishment can be proposed using the goal orientation concept. Students with extrinsic motivation might seek standards against which they can measure their performance. This effort can also be conducted by those with intrinsic motivation, but considering their reasons for learning were based more on their love for the subject (mastery goal orientation), they would not rely as much on certain standards for reassurance (18). 


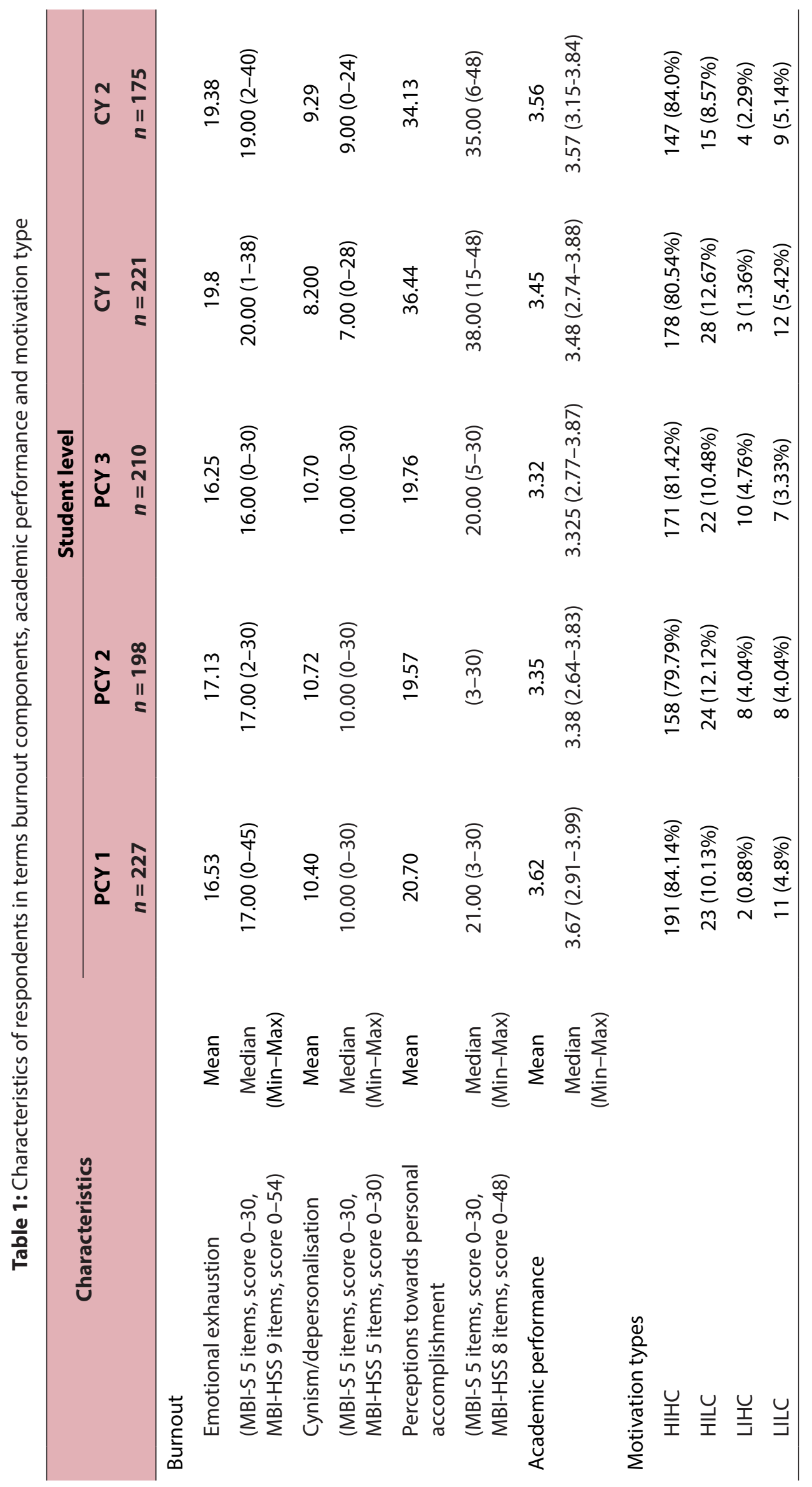


Table 2: Association between motivation, components of burnout and academic performance

\begin{tabular}{|c|c|c|c|c|c|c|c|c|c|c|}
\hline \multirow{3}{*}{ Variable } & \multicolumn{10}{|c|}{ Motivation* } \\
\hline & \multicolumn{2}{|c|}{ PCY 1} & \multicolumn{2}{|c|}{ PCY 2} & \multicolumn{2}{|c|}{ PCY 3} & \multicolumn{2}{|c|}{ CY 1} & \multicolumn{2}{|c|}{ CY 2} \\
\hline & $\boldsymbol{r}$ & $p$ & $\boldsymbol{r}$ & $p$ & $r$ & $p$ & $r$ & $p$ & $r$ & $p$ \\
\hline Academic performance & -0.027 & 0.689 & -0.007 & 0.919 & 0.064 & 0.357 & -0.08 & 0.357 & 0.077 & 0.314 \\
\hline $\begin{array}{l}\text { MBI-emotional } \\
\text { exhaustion }\end{array}$ & -0.11 & 0.872 & -0.009 & 0.903 & -0.002 & 0.978 & -0.043 & 0.978 & 0.011 & 0.881 \\
\hline MBI-cynicism & -0.087 & 0.194 & 0.017 & 0.815 & 0.06 & 0.388 & -0.022 & 0.388 & 0.054 & 0.478 \\
\hline $\begin{array}{l}\text { MBI-perception } \\
\text { of personal } \\
\text { accomplishment }\end{array}$ & -0.227 & 0.001 & -0.229 & 0.001 & -0.12 & 0.082 & -0.201 & 0.082 & -0.166 & 0.028 \\
\hline
\end{tabular}

Note: "Type of motivation (HIHC, HILC, LIHC and LILC) was converted into scores of $0-3$ respectively so that the higher score represents more external and lower motivation type.

Table 3: Multivariate analysis of burnout scales and motivation

\begin{tabular}{|c|c|c|c|c|c|c|c|c|c|c|}
\hline \multirow{3}{*}{ Variable } & \multicolumn{10}{|c|}{ Motivation } \\
\hline & \multicolumn{2}{|c|}{$\begin{array}{c}\text { Academic } \\
\text { Year } 1\end{array}$} & \multicolumn{2}{|c|}{$\begin{array}{l}\text { Academic } \\
\text { Year } 2\end{array}$} & \multicolumn{2}{|c|}{$\begin{array}{c}\text { Academic } \\
\text { Year } 3\end{array}$} & \multicolumn{2}{|c|}{ CY 1} & \multicolumn{2}{|c|}{ CY 2} \\
\hline & $r$ & $p$ & $r$ & $p$ & $r$ & $p$ & $r$ & $p$ & $r$ & $p$ \\
\hline $\begin{array}{l}\text { MBI-Perception } \\
\text { of personal } \\
\text { accomplishment }\end{array}$ & 0.061 & 0.003 & -0.206 & 0.004 & -0.138 & -0.188 & -0.242 & 0.000 & -0.189 & 0.012 \\
\hline
\end{tabular}

A tendency to rely on certain standards (i.e., comparing their own performance with peers) can also be attributed to firstyear students' limited knowledge about the curriculum (including what is expected of them) because they are still adjusting to the new environment. When these standards were somehow met, students might then feel that they have accomplished their goals. A study conducted on the role of self-efficacy on different type of motivation revealed that for individuals with lower intrinsic motivation, the role of self-efficacy in forming perceived competence was found to be important, but for those with high intrinsic motivation, the role of selfefficacy becomes less important (19). It seems that when students have high intrinsic motivation, they do not rely much on self-efficacy to deliver their performance; instead, they perform the task due more to their love of performing it. But those with low intrinsic motivation (or who are more extrinsically motivated) need to believe that they are capable of doing the task in order to perform. One possible way of acquiring self-efficacy could be by comparing their performance to that of their peers (19).

Despite findings supporting the association between intrinsic motivation and better academic performance, in the present study no significant correlation was found between the two aspects. This might imply that students' academic peformance is affected by many factors, including self-regulated learning ability. Self-regulated learning emphasises three aspects contributing to the success of learning, which are the use of self-regulated learning strategies, responsiveness to self-oriented feedback and motivations. Many factors contribute to performance, such as the implementation of an appropriate learning strategy and self-monitoring ability. Learning strategies may include planning, information seeking, record keeping, environmental structuring, rehearsing and memorising, seeking social 
assistance, and reviewing. The current study showed that students with higher academic achievements might utilise appropriate learning strategies compared to their peers with lower achievements. Simply knowing available learning strategies is not adequate for learners; they need to be able to monitor their learning process. Learners' selfmonitoring process occurs simultaneously, as learning takes place by evaluating their own progress and being reflective (20).

The findings from the present study emphasise the need to help nurture students' motivation. Intrinsically motivated students would be less likely to have a low perception of their performance, which means they would have better self-efficacy and be able to achieve a better performance. This condition would also mean that they would be more resilient and less likely to experience burnout during their study in medicine. The learning process in both academic and clinical settings should accomodate the components needed to nourish intrinsic motivation, which are students' sense of autonomy, perceived competence and sense of relatedness to their environment (17). From a self-efficacy point of view, students need to be able to assess their performance accurately against a realistic standard, have opportunities to observe others and receive encouragement and constructive feedback.

The present study did have some limitations. It was a cross-sectional study conducted at a single institution, therefore the association found between motivation and perception of personal accomplishment was a correlation and cannot be interpreted as a causal relationship. A longitudinal study is needed to further explore the change of motivation throughout medical education, including its relationship with the components of burnout. The findings from the first-year students also suggest further research is required to determine the effect of adaptation on motivation and burnout.

\section{CONCLUSION}

This study found that as motivation shifts to a more external type, perception of personal accomplishment decreases. The role of intrinsic motivation in achieving a better performance and the concept of self-efficacy can be utilised to explain the correlation. However, a positive correlation between motivation type and perception of personal accomplishment was found for first-year students, suggesting the adaptation process as confounding factors. The findings from this study also highlight the importance of intrinsic motivation and attempts to nurture this form of motivation in order to help students achieve better outcomes and to prevent them from experiencing burnout. Burnout prevention among undergraduate medical students should also accompanied by monitoring of students' motivation type.

\section{ACKNOWLEDGEMENTS}

This study was funded by PITTA Research Grant from Universitas Indonesia no 2048/ UN2.R3.1/HKP.05.00/2018. The authors would like to thank all undergraduate medical students of FMUI who participated in the study, including James Wiguna Wahjudi, Andrew Kurniawan and Johan Qomarasandhy who helped in collecting the data. The authors also highly appreciate the constructive feedback on the statistical analysis of the present study from Dr. dr. Retno Asti Werdhani, MEpid.

\section{REFERENCES}

1. Ishak W, Nikravesh R, Lederer S, Perry $\mathrm{R}$, Ogunyemi D, Bernstein C. Burnout in medical students: a systematic review. Clin Teach. 2013;10(4):242-5. https://doi. org/10.1111/tct.12014 
2. Kusurkar RA, ten Cate TJ, van Asperen M, Croiset G. Motivation as an independent and dependent variable in medical education: a review of the literature. Med Teach. 2011;33(5):e242-62. https://doi.org/ 10.3109/0142159X.2011.558539

3. Kusurkar RA, Croiset G, Galindo-Garré F, Cate OT. Motivational profiles of medical students: association with study effort, academic performance, and exhaustion. BMC Med Educ. 2013;13(87):1-8. https:// doi.org/10.1186/1472-6920-13-87

4. Gyorffy Z, Birkas E, Sandor I. Career motivation and burnout among medical students in Hungary: could altruism be a protection factor. BMC Med Educ. 2016;16:182. https://doi.org/10.1186/ s12909-016-0690-5

5. Stajkovic A, Luthans F. Social cognitive theory and self-efficacy: implications for motivation theory and practice. In: Steers RM, Portert LW, Bigley GA, editors. Motivation and work behavior. 7th ed. United States: McGraw-Hill/Irwin; 2003. p. 126-40.

6. Schunk DH. Self-efficacy for reading and writing: influence of modelling, goal setting, and self evaluation. Reading and Writing Quarterly. 2003;19:159-72. https://doi .org/10.1080/10573560308219

7. Karamooz M, Narafshan MH. The relationship between self-regulation strategies and burnout: a teacher analysis in EFL context of Iran. Studies in Linguistics and Literature. 2017;1(2):186-97. https:// doi.org/10.22158/sll.v1n2p186

8. Bandura A. Perceived self-efficacy in cognitive development and functioning. Educational Psychologist. 1993;28(2):117-48. https://doi.org/10.1207/ s15326985ep2802_3
9. Klassen R, Klassen J. Self-efficacy beliefs of medical students: a critical review. Perspectives on Medical Education. 2018;7:76-82. https://doi.org/10.1007/ s40037-018-0411-3

10. Pellacia T, Delplancq $H$, Triby E, Bartier JC, Leman C, Dupeyron JP. Impact of training periods in the emergency department on the motivation of the healthcare students to learn. Med Educ. 2009;43(5):462-9. https://doi.org/10.1111/ j.1365-2923.2009.03356.x

11. Roohi G, Asayesh H, Bathai SA, Shouri Bidgoli AR, Badeleh MT, Rahmani $H$. The relationship between self-efficacy and academic motivation among students of medical sciences. Journal of Medical Education and Development. 2013;8(1):4551 .

12. Mataroria PL, Henning MA, Alyami H, Krishna S, Zeng I, Yu TC, Hill AG. Burnout, quality of life, motivation, and academic achievement among medical students: a person-oriented approach. Perspect Med Educ. 2017;6:108-14. https:// doi.org/10.1007/s40037-017-0340-6

13. Rinn AN, Boazman J. Locus of control, academic self-concept, and academic dishonesty among high ability college students. Journal of the Scholarship of Teaching and Learning. 2014;14(4):88-114. https://doi.org/10.14434/v14i4.12770

14. Zhang X, Klassen RM, Wang Y. Academic motivation and burnout of Chinese secondary students. International Journal of Social Science and Humanity. 2013;3(2):134-8. https://doi.org/10.7763/ IJSSH.2013.V3.212

15. Qomarasandhi J. Pengaruh tipe motivasi terhadap burnout pada mahasiswa tahap klinik Fakultas Kedokteran Universitas Indonesia [dissertation]. Jakarta: Universitas Indonesia; 2017. 
16. Chang E, Lee A, Byeon E, Lee SM. Role of motivation on the relation between perfectionism and academic burnout in Korean students. Personality and Individual Differences 2015;82:221-6. https://doi .org/10.1016/j.paid.2015.03.027

17. Wouters A, Croiset G, Galindo-Garre F, Kusurkar RA. Motivations of medical students: selection by motivation or motivation by selection. BMC Med Educ. 2016;16:37. https://doi.org/10.1186/s12909016-0560-1

18. D'Lima GM, Winsler A, Kitsantas A. Ethnic and gender differences in first-year college students' goal orientation, sefl-efficacy, and extrinsic and intrinsic motivation. Journal of Educational Research. 2014;107:341-56. https://doi.org/10.1080/00220671.2013.823 366
19. Buch R, Safvenbom R, Boe O. The relationship between academic selfefficacy, intrinsic motivation, and perceived competence. Journal of Military Studies. 2015;6(1):19-35. https://doi.org/10.1515/ jms-2016-0195

20. Zimmerman BJ. Self-regulated learning and academic achievement: an overview. Educational Psychologist. 1990;25(1):3-17. https://doi.org/10.1207/s15326985ep2501_2 